\title{
RESILIENCE OF TRANSPORT INFRASTRUCTURE SYSTEMS
}

\author{
Pekka Leviäkangas, Aki Aapaoja*
}

Department Transport, VTT Technical Research Centre of Finland Ltd., Oulu, Finland

(Received: January 2015 / Revised: February 2015/ Accepted: April 2015)

\begin{abstract}
This paper proposes a generic resilience framework that is applied to transport infrastructure systems. The framework is based on prior research and literature material on resilience. The paper first reviews some of the relevant literature and builds a resilience model that distinguishes the attributes and sub-attributes of resilience. Then the resilience model and transport system components are merged into single system resilience matrix. The complexity of resilience of a meta-system - a system comprising several sub-systems - is underlined. Finally, the implications on other meta-systems, for example those governed by cities and municipalities, are briefly discussed. In fact, cities and municipalities face even a more complex resilience analysis tasks than do the state authorities who mostly govern sector systems (e.g. transport) within their mandate.
\end{abstract}

Keywords: Infrastructure, Resilience, Reliability, Vulnerability, Transport

\section{INTRODUCTION}

On 5th of December in 2013 the Council of State of Finland decided that one of the priority objectives of the national transport system is reliability, ensuring the supply security of the nation and different parts of the country in all circumstances. The state authorities were made responsible to secure the functioning of the transport system and in particular the availability infrastructures that form the backbone of the system. Land transport networks, ports, aviation nodes, strategic terminals, information and communication as well as safety and energy systems were explicitly mentioned. In principle, the transport system must function in all circumstances and situations. The assuring of the system functioning includes assessment of critical parts and objects, their risks from a holistic perspective and recovering ability from shocks. (Ministry of Employment and the Economy, 2013).

Although reliability, resilience and other related terms are used and applied widely, uniform globally accepted definitions are not there. The semantics of terms is dependent on the context and meanings are contingent. Reliability and resilience can be understood to be almost synonymous. In international contexts, resilience is already widely adopted to reflect the ability of systems to withstand shocks and maintain their capabilities. Also the ability to recover quickly from shocks is associated as an attribute to resilience (see e.g. European Environment Agency, 2014).

During the last decade or so, resilience has become the buzz word not only related to infrastructures but earlier in association of international policy (see e.g. UNISDR 2007; Bruneau et al., 2003; Little, 2003).

\footnotetext{
"Corresponding author. E-mail:aki.aapaoja @ vtt.fi, Tel., +358 40744 4823, fax: +358 207222320
} 
Depending on the context and culture, resilience is understood differently. What is usually common is that resilience is understood as rather technical heuristically valuable concept when addressing critical qualities of societies and communities. Critical infrastructures are typically one embodiment of the use of the concept. For example in Finland resilience is commonly used in connection with national security of supply and protecting critical infrastructures (Juntunen, 2014).

The origin of resilience - right after the biological and medical usage - is in the socioeconomic ecosystems, the ability and capacity of which to absorb disturbances, shocks or impacts while maintaining its capability to function and to reform or recover to its original state. Resilience is system's somewhat hidden feature which is revealed only after shock or impact is encountered (Juntunen, 2014). Below a couple of alternative resilience definitions are given. Though their slightly different formulation, it is easy to capture the common message:

- "The capacity of a system, community or society potentially exposed to hazards to adapt, by resisting or changing in order to restore or maintain an acceptable level of functioning and structure" (ARMONIA, 2006)

- "The ability to prepare for and adapt to changing conditions and withstand and recover rapidly from disruptions. Resilience includes the ability to withstand and recover from disturbances of the deliberate attack types, accidents, or naturally occurring threats or incidents. System resilience for a particular function can be measured based on the persistence under uncertainty of a corresponding system's performance in the face of disturbances" (Ayyub, 2013)

- The ability of a system, community or society exposed to hazards to resist, absorb, accommodate to and recover from the effects of a hazard in a timely and efficient manner, including through the preservation and restoration of its essential basic structures and functions. (UNISDR, 2009)

Ojanen (2008) states that it is not possible to be successful in ensuring resilient and reliable functions of the society unless the processes, mechanisms and most importantly, attitudes and mindset, can tolerate substantial uncertainties, unpredictable events and lack of routines in unforeseen situations. Tolerance for the unexpected, and yet maintaining operational capability, is a key indicator of resilience or reliability. Ojanen underlines that success in reliability is the ability of holding the desired course in an increasingly turbulent world where the unexpected is taking place anyhow. The challenges, impacts and problems furthermore can, and may even have a tendency to be combined in a surprising manner. (Homer-Dixon, 2006)

Resilience is not obviously too far from reliability. Especially reliability in cases where unexpected, unforeseen and sudden adverse events occur, combined with several systems interacting in an unexpected manner, accumulating the adverse effects, can be considered as resilience too. It is virtually impossible to count for all possible events and accumulating effects due to our limited understanding, knowledge and experience (Hanén \& Huhtinen, 2011). For this reason it must be understood that resilience is never perfect and it can never be made such. Surprises and randomness will always play their role. One thing that could be learned from this is that those systems that already are more reliable (and hence more resilient) than others could be favoured in resilience building. Some studies suggest this strategy also for transport policy decision making: favouring reliable sub-systems is making the transport system more resilient (Walker et al., 2011; Leviäkangas \& Michaelides, 2014).

Only sustainable and long-term approaches can be considered to result in solutions be they decisions, investments or strategies - that deliver resilience (Walker et al., 2011). Tobin (1999) has stated that resilient and sustainable communities are identified on the basis of systematic management of different functions. Hence well-organised communities or 
functions should be more resilient than those less so. Moreover, resilience is not situationspecific but a more generic ability that considers multiple aspects, such as economic, environmental and social ones (Ayyub, 2014).

This article aims to examine the concept of transport infrastructure resilience and dismantle the components and subcomponents of resilience at conceptual level. The subcomponents we call attributes. We shall also investigate how the components and attributes can be operationalized, measured and valued, if at all. One of the topics is of course to consider if components and their sub-parts can be aggregated in a meaningful way to assess the overall resilience of transport system infrastructures. As goes without saying, also transport system comprises several subsystems that have different characteristics and logic in their modus operandi. By disaggregating the concept of resilience, operationalizing it and giving it scalable indicators we make the concept more manageable for the practitioners, infrastructure owners and caretakers as well as for the decision makers are responsible for keeping the transport system in a condition that enables it to serve its purpose. Moreover, by doing the aforementioned analysis, we hope to contribute to investment and system planning, where resilience is anyway either explicitly or implicitly present as one key decision and design criterion.

We shall apply our resilience model to transport infrastructure system context and depict the model as a framework or matrix which can be used as a starting point in the engineering or assessment of transport system resilience. Needless to say, any framework of the aforementioned qualities is bound not to be exhaustive, but a rough tool that lowers the threshold of resilience enhancing efforts. Designing for or appraising existing resilience is a holistic, extensive task where it is more than easy to focus the work to cover only minor details or be overwhelmed by the countless number of issues and viewpoints that are supposed to be covered. Finally, we discuss the implications to quantitative modelling which has been already attempted in other contexts. The novelty, we believe, lies in the disaggregation of resilience and reflecting the components and attributes against multiple components of multi-modal transport system. We take the resolution of resilience one step further.

Our article rests on existing literature for most parts, but the disaggregation of components into more detailed attributes is not yet found in published form as we present it. Hence the conceptual model for transport system resilience can be regarded as a constructive approach to derive a tool for more practical purposes, delivering some instrumental value. The model is suggested to be applied and further to be developed and operationalised by the Finnish Transport Safety Agency, the responsibility of which is in addition to safety also some reliability aspects of the transport system. The need for resilience conceptualisation became evident, as the Agency's management system was thoroughly evaluated (Mononen \& Leviäkangas, 2015).

\section{RESILIENCE MODEL}

\subsection{Resilience in Transport Systems}

One of recent resilience research areas in transport has been related to climate change and extreme weather. Several European Framework projects as well as an abundance of efforts from rest of the world have been published (Michaelides et al., 2014; Leviäkangas \& Michaelides, 2014; Molarius et al., 2014; Samberg et al., 2011; Croope \& McNeil, 2011; Taylor \& Philip, 2010). Often resilience is not even explicitly mentioned, but alternative terms and concepts such as sustainability are used, which can be associated with long-term resilience of the system. The perspectives and scopes vary, though, from energy to social aspects. Our paper takes a more technical and socio-economic view. 
Extreme weather hazards and damages it causes to transport system have gained much attention. Climate change discussion obviously has been one of the drivers to this direction although the adverse weather events have equally raised awareness (most likely as a partial result of climate change awareness). Both aspects require actions now if we consider the lifecycle of any transport infrastructure asset. It is obvious that the more durable and resilient we build (and maintain) our transport systems, the less resources are committed in the future to keep them going and serving. This approach weighs the front-end investments and spending in order to keep resource consumption at reasonable level in the future. Hence it is not only new investments that deserve our attention, but also the asset management strategies, maintenance programs, etc. that must be considered more of an investment rather than a budget spending line. Moderate upgrades, enhanced and proactive maintenance, more effective information sharing (e.g. engineering design documents) are examples where lifecycle costs can be lower than with laissez-fair approach (Walker et al., 2011; Leviäkangas \& Michaelides, 2014). It should be noted, however, that the strategies of developing economies, where new infrastructure is still gravely needed, will differ those of more developed economies where existing infrastructure will require increasing attention. A resilient transport system, as any system, will most likely be also more efficient in the long run as well as safer (Hollnagel, 2010).

Systems that cover wide areas are more vulnerable if the system components or links are dependent on each other in reliability sense, whereas system components that are nodes are at hazard once the shock hits them. Both system topologies are vulnerable, but with different conditions and in different ways (Leviäkangas et al., 2011a). It has also been noted that whenever risk and contingency management is based on assumptions that the risks and incidents can be assessed analytically ex ante, resilience is by definition also expecting the unexpected and takes into account the absorption, recovery and elasticity characteristic. This way the ability to maintain critical service level, that may well be lowered substantially, is yet sustained to the extent that the society's functions can still continue (Pelttari, 2014; Walker et al., 2011). As the social and technical features of transport systems develop more complex and interlocked, their resilience is dictated ever more by the combined effects and how resilience is behaving as effects either dampen or amplify each other (Doll et al., 2014).

One of the most cost-effective means to enhance resilience is information. Once one mode of transportation fails (e.g., train), the information on the nature of the failure, its duration and alternative services available for passengers, is clearly an attribute of resilience. Passenger information has been earlier associated with service level and comfort, but in fact it has more dimensions than just those. A good example took place in Europe in 2010. The eruptions of Eyjafjallajökull in Iceland caused unprecedented disruption to air travel across western and northern Europe over an initial period of six days in April 2010. Some 20 countries closed their airspace affecting about 10 million travellers (Bye, 2011). The information on trains, buses and car rental options was insufficient and the alternative services' customer interfaces could not deal with the sudden information demand. Likewise, the rail operators and infrastructure managers of Europe were caught entirely by surprise and were unable to extend the capacity as needed.

\subsection{Components of Resilience}

As we consider resilience, the aggregate concept is not sufficient. We should be able to distinguish which components comprise resilience so that the object becomes more manageable and performance metrics can be devised. In plain words, the idea is to slice the concept into components that are measurable or at least more easily assessable. According to Walker et al. (2011) resilience is the inverse of vulnerability, yet having the same components. Vulnerability, in turn, can be defied as a function of exposure, susceptibility and 
coping capacity as defined by multiple sources (UNISDR, 2009; White et al., 2005; Molarius et al., 2014).

Disaster Reduction Institute (UNISDR, 2009) has given the following definitions to the aforementioned:

- Coping capacity: the ability of people, organizations and systems, to use available skills and resources in order to face and manage adverse conditions, emergencies or disasters.

- Exposure: people, property, systems, or other elements present in hazard zones that are thereby subject to potential losses.

- Vulnerability: the characteristics and circumstances of community, system or asset that make it susceptible to the damaging effects of a hazard.

In addition we use the following definition for susceptibility: state or character of being capable of receiving, admitting, undergoing, or being affected by some harmful effect. This was given in Molarius et al. (2014) that further present the following conceptual model for vulnerability and resilience (eq. 1) based on the above definitions and hierarchy:

$$
\begin{gathered}
\text { Vulnerability }=\frac{\text { Exposure } \times \text { Susceptibility }}{\text { Coping capacity }}=\frac{1}{\text { Resilience }} \\
\rightarrow \text { Resilience }=\frac{\text { Coping capacity }}{\text { Exposure } \times \text { Susceptibility }}
\end{gathered}
$$

An application of the above resilience model can be found in Leviäkangas et al. (2013) and Molarius et al. (2014). Using relatively simple statistical data available in World Economic Forum publications and applying discrete scaling resilience indexes were calculated for European Union member states.

\subsection{Subcomponents, attributes}

The components of resilience can be dismantled into subcomponents or attributes, as we shall name them. The level of detail one wants to go in the hierarchy depends on the needs of the analysis at hands. The choice is first and foremost pragmatic, i.e. whatever serves the purpose best. Of course, the more solid is the scientific rationale the better, but one should not overemphasise the formal correctness at the cost of practical needs when analysis is serving normative aims. The following disaggregation of components is based on authors' own constructive analysis, deviating from previous chapter where widely agreed definitions were used. As goes without saying, the suggested model can (and probably should) be revised and improved by future research, hence our model being propositional.

Exposure can be divided in several ways. Some definitions originate quite far away in the past, e.g. related to medicine (one of the first Levin, 1953), and economics, e.g. financial risks associated with foreign currency exposure. Exposure can be dependent on the probability of adverse effect taking place. For instance, coastal roads are more exposed to sea storms, flat land roads to flooding and mountain area roads to landslides and avalanches. Exposure can also be a result of certain feature, a weakness that exposes the structure or system element to hazard or risk, independent on the probability of the hazard. For example, railway safety and control systems are exposed to lightning strikes that commonly create disturbance to the traffic. Safety and control system components can be more or less protected against lightning. Therefore we divide exposure into two attributes: risk and weakness/feature. The former refers to probabilistic exogenous factor causing adverse impact and the latter to endogenous character of the object.

Susceptibility can be divided into sensitivity and covariance. Sensitivity can be regarded as one or several qualities which make the attribute behave in a volatile manner as 
the adverse event occurs. Sensitiveness could be a result of non-robust technology, structural weakness or merely a result of complexity, as number of interlocked system elements are exposed simultaneously thus increasing the probability of failure - a typical feature with complex systems. We regard sensitivity as a purely endogenous attribute. For example, intelligent transport systems contain many features of sensitivity: they are complex, depend on other systems (e.g. telecommunications) and embed high (and sensitive) technologies.

The other attribute can be described as covariance. Covariance, being a mathematical concept, depicts how precisely the changes of parameter one is followed by parameter two. Covariance is typically applied to financial economics, as a stock's tendency to follow general stock market movements is described. Simple mathematical representation is $\operatorname{cov}(X, Y)=E(X Y)-E(X) E(Y)$, meaning in short that if random variables $X$ and $Y$ are perfectly independent, covariance is nil, and if they are perfectly dependent covariance is 1 . Perfectly inverse dependence between $X$ and $Y$ results in covariance being -1; $E$ serves as expectancy operator (see any standard mathematical statistics textbook or e.g. Encylopedia Mathematica). Applied to transport system, one can picture for example failures of computer systems or electricity supply systems that will immediately be followed by disturbances in aviation and electrified rail transport - the covariance factor is apparent. Covariance attribute can also be exogenous in nature, but this is depending on how the "system" itself is scoped.

Coping capacity is by definition the abilities to cope with adverse impacts. Available resources - economic, technical, institutional, etc. - dictate much of the capacity. Wealthy, technically advanced and well-organised communities are in better position to withstand and recover from shocks. Usually these communities have better infrastructures too, that are better protected and of high quality: these infrastructures are "hedged" against some risks. The overall skills of these communities are likewise good. Good organisation tends to indicate attitudes that lead to better level of preparedness. These attributes are by no means necessarily independent, but rather form a network of dependencies. The network of attributes could well be as strong (resilient) as its weakest link or node. We divide coping capacity into attributes of resources, hedging, skills, and an inverse of weakness-features, listed in adjunction with exposure. The mathematical conceptualisation is formulated (eq. 2) below:

$$
\text { Resilience }=\frac{\text { Resources, Skills, Features } \text { strenght }, \text { Hedging }}{\text { Risk, Features }}
$$

Figure 1 depicts our resilience conceptual hierarchy. The dotted lines between attributes represent our own perception (hypothetical) of the attributes' interdependencies. However, at this point of the model construct, these require more solid analysis and therefore they remain just to hint that these interdependencies can be meaningful in further model development.

To further illustrate the potential use of the devised resilience model, we can exemplify how different metrics could be incorporated to the model:

- Risk $=>$ probability of adverse event, e.g. probability of a storm

- Weakness feature $=>$ outdated infrastructure component at the end of its technical service life or obvious poor quality

- Sensitivity => non-robust or unprotected components of the system

- Covariance $=>$ dependency on other system components or other systems (e.g. electricity power supply)

- Resources => availability and quality of repair equipment, budget adequacy 
- Skills $\Rightarrow$ trained maintenance and repair crews, sophistication of asset management strategies

- Strength features => robust designs, engineering and design philosophy (e.g. use of safety multipliers or factors)

- Hedging $\Rightarrow$ protective structures, insurance.

All the above attributes are more or less measurable and can be integrated into resilience index or other type of descriptive quantity.

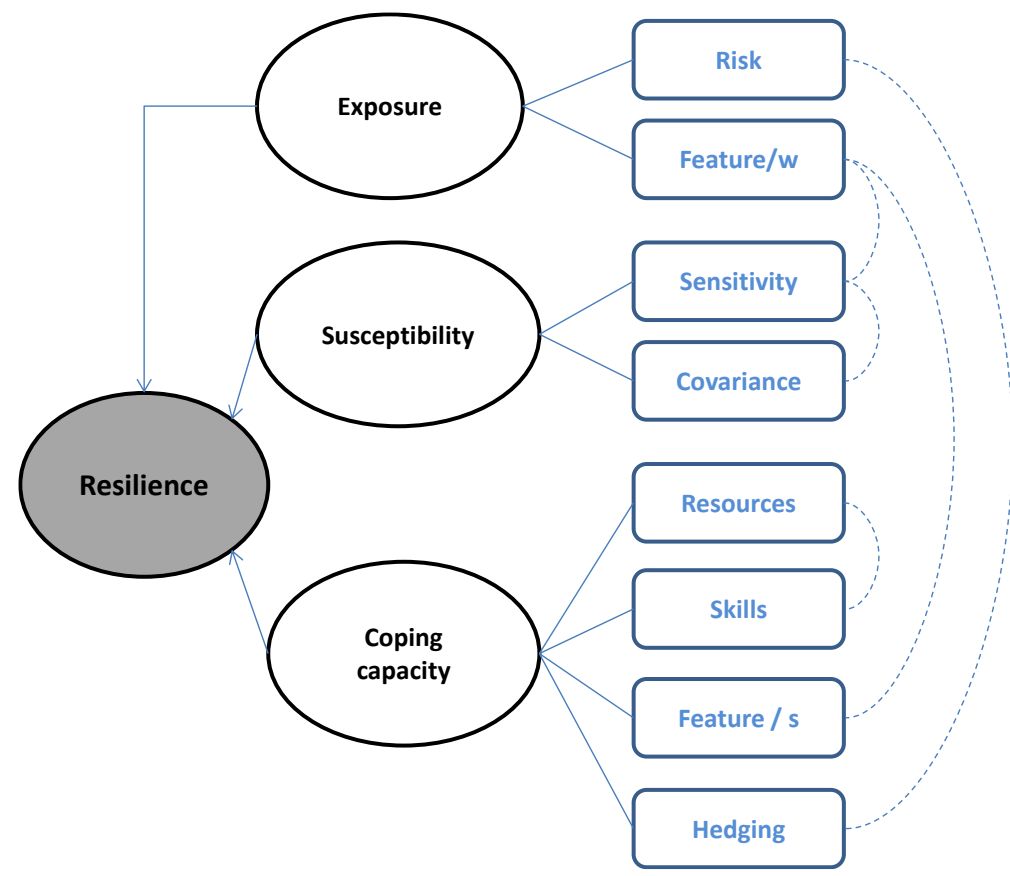

Figure 1. Resilience, its components and attributes.

\section{EMBEDDING THE RESILIENCE MODEL TO THE TRANSPORT SYSTEM}

\subsection{Components of Transport System}

Applying the concept of resilience to transport systems is demanding for several reasons. First, the transport system comprises several interconnected subsystems that even alone are complex. Secondly the modes - road, rail, aviation, maritime - are very different in many respects: technology, capacity, governance, market, etc. Their resilience attributes may be the same following our framework, but these attributes may have very different weights. Also the subsystems of each mode are far from identical. For example, in rail system we can distinguish several noteworthy subsystems: rails and their substructures, electricity, communications, safety, control, not to mention stations, rolling stock, terminals, shunting yards, etc. Some of these systems are more or less generic, particularly in technology respect, but their management, governance and ownership varies between countries. Yet the rail system can be regarded as an international system, usually connecting nations logistically, as do maritime and aviation systems.

Any physical infrastructure and the system they represent (as a system by themselves or as a subsystem) can be divided into subsystems. Table 1 presents one option to divide transport system into manageable subsystems. Light traffic includes pedestrians, cycling and all non-motorized traffic. In addition to infrastructures, transport system can include vehicles, operators, administration and system related businesses and services. Also freight and passenger systems are typically viewed as independent subsystems. However, any fixed or 
generally accepted definition of what comprises the total transport system is not available though attempts are innumerable.

Table 1. Transport infrastructure system and subsystems.

\begin{tabular}{llll}
\hline $\begin{array}{c}\text { Modal } \\
\text { "pathways" }\end{array}$ & $\begin{array}{c}\text { Supplementing } \\
\text { structures }\end{array}$ & \multicolumn{1}{c}{ Subsystems } & \multicolumn{1}{c}{ Nodes } \\
\hline Roads & Bridges, tunnels & $\begin{array}{l}\text { Lighting, signalling, drainage, ITS- } \\
\text { systems, traffic management centres }\end{array}$ & $\begin{array}{l}\text { Dry land } \\
\text { terminals, stations, } \\
\text { border crossings, } \\
\text { nodes connecting } \\
\text { to other modes } \\
\text { Terminals, } \\
\text { stations, shunting } \\
\text { Rails }\end{array}$ \\
& Bridges, tunnels & $\begin{array}{l}\text { Information systems, electricity, } \\
\text { safety, control and traffic } \\
\text { management systems }\end{array}$ & $\begin{array}{l}\text { yards, ports } \\
\text { Ports }\end{array}$ \\
Waterways, signalling, vessel traffic \\
Aviation & $\begin{array}{l}\text { Port structures, } \\
\text { channels, gates } \\
\text { Connecting land } \\
\text { transport structures } \\
\text { Bridges, tunnels }\end{array}$ & $\begin{array}{l}\text { Traffic control, safety and security } \\
\text { systems, information systems } \\
\text { Lighting, signalling, drainage }\end{array}$ & Airports \\
$\begin{array}{l}\text { Light } \\
\text { traffic }\end{array}$ & $\begin{array}{l}\text { Stations, shopping } \\
\text { centres }\end{array}$ \\
\hline
\end{tabular}

\subsection{Resilience - Transport System Matrix}

The resilience as well as other qualities of subsystems is different. The components and attributes of resilience are likewise varyingly emphasised. Therefore a uniform approach how to manage or enhance resilience does not necessarily exist. However, some tools that can be applied across systems and subsystems can be found, and in particular when some generic approaches are available. In Table 2, the generic resilience component and attribute structure is combined with transport infrastructure system model. The idea is that multiple needs can be accommodated with the resilience matrix. The matrix can be modified, expanded, simplified and improved according to needs. The authors used the matrix to aid the Finnish Transport Safety Agency to a) capture the potential metrics of resilience, b) to assess each resilience attribute's quantitative valuation potential (Leviäkangas \& Aapaoja, 2015).

The ownership and governance structures are in key role when resilience enhancing strategies are put in place. The ownership and governance issues are not as evident as one might think at first glance (see e.g. Leviäkangas et al., 2011b). Who needs resilience? Who is willing to pay for it? Who will be bearing costs? How to ensure interoperability and substitution in case of sub-system meltdown? These are the type of questions that emerge when resilience investments, either as part of new investments or as long-term strategic resource allocations (e.g. maintenance programs), are considered and appraised. 
Table 2. Resilience - transport system matrix

\begin{tabular}{|c|c|c|c|c|c|c|c|c|c|}
\hline \multirow{3}{*}{\multicolumn{2}{|c|}{ Transport subsystem }} & \multicolumn{8}{|c|}{ Resilience } \\
\hline & & \multicolumn{2}{|c|}{ Exposure } & \multicolumn{2}{|c|}{ Susceptibility } & \multicolumn{4}{|c|}{ Coping capacity } \\
\hline & & & 3 & 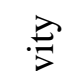 & $\underset{\Xi}{\Xi}$ & d్ & & $\frac{\infty}{\infty}$ & \\
\hline \multirow{3}{*}{ 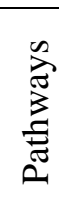 } & $\begin{array}{l}\text { Roads, streets, light } \\
\text { traffic pathways }\end{array}$ & & & & & & & & \\
\hline & Rails & & & & & & & & \\
\hline & Waterways & & & & & & & & \\
\hline \multicolumn{10}{|c|}{ Nodal points } \\
\hline \multicolumn{10}{|c|}{ Supplementing structures } \\
\hline \multicolumn{2}{|c|}{ Supplementing systems } & & & & & & & & \\
\hline
\end{tabular}

\section{CONCLUSION}

Resilience can be divided into components and sub-components as any semantic concept. The aim for disaggregating the concept is to make resilience manageable, measurable and understandable. In this paper one prospective way was shown how resilience can be defined and how it can be applied to transport systems. However, the presented models are constructed pragmatic purposes in mind. The ideas were delivered to Finnish Transport Safety Agency in order to allow the agency to take a better grip of resilience and to offer insight how the agency is better able to seek resilience enhancing approaches that fall within its mandate.

It is suggested that rather than trying to solve all resilience challenges at once, the suggested framework enables slicing the challenges into subsystems and investigate each resilience component and attribute at a time. It is the perception of the authors that much of the discussion on resilience is still carried out at rather general level. The proposed approach provides some tools to overcome the problem of too general views and paves the way for more detailed, structured analysis.

Especially authorities, both state and local can decide where to focus their first efforts as resilience strategies are called for, without forgetting what other aspects need to be considered later or by other parties. Local level governments, who responsible for not only transport systems, but also even more critical infrastructures such as water supply, sanitation, energy and electricity. Therefore, local authorities could in fact face an even more serious challenge to prioritise their efforts and to assess interdependencies of different infrastructures. Traditional hierarchy of needs offers one means of focus and priority seeking. For example, water and energy supply will most likely override mobility needs. Resilience challenges will bring complex system analysis to the table of decision makers.

\section{REFERENCES}

ARMONIA Project (2006) Deliverable 5.1. http://www.armoniaproject.net.

Ayyub, BM., (2013), Systems Resilience for Multi-Hazard Environments: Definition, Metrics and Valuation for Decision Making. Risk Analysis, Vol. 34, Issue 2, pp. 340-355.

Ayyub, BM., (2014), Resilience Metrics for Multi-Hazard Environments. Vulnerability, Uncertainty, and Risk, pp. 925-936, ASCE (American Society of Civil Engineers). 
Bruneau, M., Chang, SE., Eguchi, RT., Lee, GC., O'Rourke, TD., Reinhorn, AM., Shinozuka, M., Tierney, K., Wallace, WA., and von Winterfeldt, D. (2003), A Framework to Quantitatively Assess and Enhance the Seismic Resilience of Communities. Earthquake Spectra, vol. 19, pp. 733-752.

Bye, BL., (2011), Volcanic eruptions: Science and Risk Management, Science 2.0.

Croope, SV. and McNei, S. (2011), Improving Resilience of Critical Infrastructure Systems Postdisaster. Transportation Research Record: Journal of the Transportation Research Board, Volume 2234, Issue 1, pp 3 - 13.

Doll, C., Kühn, A., Peters, A., Juga, I., Kral, S., Enei, R., Pietroni, F., Mitsakis, E., Stamos, I., Schultmann, M., Wiens, M., Schätter, F., Meng, S., Bartsch, M., Kynnös, K., Hietajärvi, A-M., Kostiainen, J., Mantsinen, H., and Hinkka, V. (2014), Guidebook for Enhancing Resilience of European Road Transport in Extreme Weather Events. MOWE-IT D4project report.

European Environment Agency (2014), Adaptation of transport to climate change in Europe Challenges and options across modes and stakeholders, EEA Report No 8/2014.

Hanén, T. and Huhtinen, A-M., (2011), Yhteenkietoutumisen teoria - yllätysten ja sattuman tieteellinen selitys. Tiede ja ase, vol. 69, pp. 9-33.

Hollnagel, E., Pariès, J., Woods, DD., Wreathall, J., (2010), Resilience Engineering in Practice: A Guidebook, Ashgate, USA.

Homer-Dixon, T., (2006), The Upside of Down: Catastrophe, Creativity, and the Renewal of Civilization. Island Press, Washington, D.C., USA.

Juntunen, T., (2014), Kohti varautumisen ja selviytymisen kulttuuria? kriittisiä näkökulmia resilienssiin. SPEK Puheenvuoroja 2, Tampere.

Levin, ML., (1953), The occurrence of lung cancer in man. Acta Unio Int Contra Cancrum, Volume 9, Number, pp. 531-541.

Leviäkangas, P., and Aapaoja, A., (2015, forthcoming). Resilienssin käsite ja operationalisointi - case liikennejärjestelmä [The concept of resilience and its operationalization - case transport systems]. Kunnallistieteellinen aikakauskirja. In Finnish only.

Leviäkangas, P. and Michaelides, S., (2014), Transport system management under extreme weather risks: views to project appraisal, asset value protection and risk-aware system management. Natural Hazards, Volume 72, Number 1, pp. 263-286, Springer.

Leviäkangas, P., Molarius, R., Könönen, V., Hietajärvi A-M. and Zulkarnain (2013), Devising and Demonstrating an Extreme Weather Risk Indicator for Transportation System. Transportation Research Record, Journal of the Transportation Research Board, Volume 2329, 2013, pp 45-53

Leviäkangas, P., Nokkala, M., Rönty, J., Talvitie, A., Pakkala, P., Haapasalo, H., Herrala, M. and Finnilä, K., (2011b), Ownership and governance of Finnish infrastructure networks. VTT Publications 777. VTT, Espoo, Finland.

Leviäkangas, P., Tuominen, A., Molarius, R., Kojo, H., Schabel, J., Toivonen, S., Keränen, J., Ludvigsen, J., Vajda, A., Tuomenvirta, H., Juga, I., Nurmi, P., Rauhala, J., Rehm, F., Gerz, T., Muehlhausen, T., Schweighofer, J., Michaelides, S., Papadakis, M., Dotzek, N. and Groenemeijer, P., (2011a). Extreme weather impacts on transport systems: EWENT Project Deliverable D1. VTT WORKING PAPERS 168, Espoo, Finland.

Little, RG., (2003), Toward More Robust Infrastructure: Observations on Improving the Resilience and Reliability of Critical Systems. In Proceedings of the 36th Annual Hawaii International Conference Hawaii, IEEE, pp. 1-9.

Michaelides, S., Leviäkangas, P., Doll, C. and Heyndrickx, C., (2014) Foreward: EU-funded projects on extreme and high-impact weather challenging European transport systems. Natural Hazards, Volume 72, Issue 1, pp 5-22, Springer. 
Ministry of Employment and the Economy (2013). Valtioneuvoston päätös huoltovarmuuden tavoitteista. Helsinki 5.12.2013.

http://www.tem.fi/files/38223/Valtioneuvoston_paatos_huoltovarmuuden_tavoitteista_0 51213.pdf

Molarius, R., Könönen, V., Leviäkangas, P., Rönty, J., Hietajärvi, AM. and Oiva, K., (2014), The extreme weather risk indicators (EWRI) for the European transport system. Natural Hazards, 72(1), 189-210, Springer.

Mononen, P. and Leviäkangas, P. (2015, forthcoming), Transport Safety Agency's Success Indicators - How Well Does a Performance Management System Perform? Transport Policy.

Ojanen, T., (2008), Kohti kestäviä strategioita: selvitys ministeriöiden keskeisten politiikkaohjelmien yhteensopivuudesta kansallisen kestävän kehityksen strategian kanssa ja pohdintaa tulevaisuuden kestävän kehityksen valtiopolitiikasta. Ministry of the Environment, kestävän kehityksen sihteeristö, Helsinki.

Pelttari, H., (2014), Resilienssiä etsimässä. Blog of National Emergency Supply Agency, published $7^{\text {th }}$ January 2014.

Samberg, S., Bassok, A. and Holman, S., (2011), Method for Evaluation of Sustainable Transportation - Toward a Comprehensive Approach. Transportation Research Record: Journal of the Transportation Research Board, Volume 2242, Issue 1, pp 1-8.

Taylor, MAP. and Philip, M., (2010), Adapting to climate change - implications for transport infrastructure,transport systems and travel behaviour. Road \& Transport Research Volume 19, Number 4.

Tobin, GA., (1999), Sustainability and community resilience: the holy grail of hazards planning? Global Environmental Change Part B: Environmental Hazards, Volume 1, Number 1, pp. 13-25.

UNISDR, (2007). Hyogo Framework for Action 2005-2015: Building the Resilience of Nations and Communities to Disasters, Geneva, Switzerland, http://www.unisdr.org/files/1037_hyogoframeworkforactionenglish.pdf

UNISDR, (2009), The United Nations International strategy for disaster reduction (UNISDR) terminology, Geneva,Switzerland, http://www.unisdr.org/files/7817_UNISDRTerminologyEnglish.pdf

Walker, G., Deeming, H., Margottini, C. and Menoni, S., (2011), Introduction to sustainable risk mitigation for a more resilient Europe. In Menoni S \& Margottini C (Eds.) Inside Risk: A Strategy for Sustainable Risk Mitigation, Springer Milan, Italy, pp. 369.

White, P., Pelling, M., Sen, K., Seddon, D., Russel, S. and Few, R., (2005), Disaster risk reduction. A development concerns, A scoping study on links between disaster risk reduction, poverty and development, Department for International Development, DFID, UK. 